\title{
EL SISTEMA DE LA PROTEÍNA C ACTIVADA EN EL CUADRO SÉPTICO
}

\author{
Carlos Hugo Escobar Soto MD*, Mario Gómez Duque MD**, César Enciso Olivera MD***
}

\section{Resumen}

Durante los últimos años y con el advenimiento del conocimiento y las técnicas de biología molecular, las concepciones fisiopatológicas del cuadro séptico han cambiado en forma dramática. Prueba de ello es la aprobación del empleo de formas recombinantes de la proteína $\mathrm{C}$ activada por parte de la Administración Federal de Alimentos y Medicamentos de Estados Unidos (FDA). Con la presente revisión se pretende hacer un análisis del estado general del conocimiento respecto al papel que la proteína $\mathrm{C}$ activada y su sistema de respuesta cumplen en el contexto del cuadro séptico.

Palabras clave: proteina $\mathrm{C}$, sepsis, morbimortalidad, vitamina $\mathrm{K}$, apoptosis.

\section{THE EFFECTS OF ACTIVATED PROTEIN C ON THE SEPSIS SYNDROME}

\begin{abstract}
The concepts on the pathophysiology of the clinical manifestations of sepsis have changed dramatically during recent years due to the development of knowledge and techniques in molecular biology. Aproof of this is the approval by the US Food and Drug Administration (FDA) of the use of recombinant forms of activated protein $C$. This review attempts to analyze the overall state of knowledge regarding the role activated protein $\mathrm{C}$ and its response system play on the sepsis syndrome.
\end{abstract}

Key words: protein C, sepsis, morbidity/mortality, vitamin $\mathrm{K}$, apoptosis.

Fecha recibido: noviembre 23 de 2010 - Fecha aceptado: diciembre 10 de 2010

* Msc. Grupo CBS - Fundación Universitaria de Ciencias de la Salud Bogotá DC. Colombia.

** Profesor Titular de Medicina Crítica. Grupo CIMCA (Centro de Investigación en Medicina Crítica Aguda). Fundación Universitaria de Ciencias de la Salud. FCCM. Bogotá DC. Colombia.
Instructor Asociado. Facultad de Medicina. Fundación Universitaria de Ciencias de la Salud. Jefe de la Unidad de Cuidado Intensivo. Hospital Infantil Universitario de San José, Bogotá DC. Colombia. 


\section{La sepsis}

La sepsis sigue siendo, a pesar de los esfuerzos y recursos invertidos, una de las principales causas mundiales de morbimortalidad. ${ }^{1,2,3}$ Ha sido considerada como un trastorno generado por una respuesta inflamatoria exacerbada. ${ }^{4,5,6}$ Estudios recientes tanto in vitro como in vivo, han demostrado que esta concepción es equivoca$\mathrm{da}^{7,8,9} \mathrm{e}$ incluso experimentos clínicos han confirmado que nuestros conocimientos fisiopatológicos al respecto, aún pierden de vista una enorme cantidad de variables involucradas. ${ }^{10-14}$

\section{La proteína}

La proteína $\mathrm{C}$ activada ( $\mathrm{aPC}$, por su nombre en inglés) es una proteasa plasmática de serina dependiente de la vitamina K. Su actividad citoprotectora se debe a la represión de la respuesta inflamatoria y de la cascada intrínseca y extrínseca de la apoptosis. ${ }^{15}$ Es producida en su forma inactiva (zimógeno) que al ser clivada por la trombina se convierte en forma activa (aPC). ${ }^{15}$

El gen humano (conocido como PROC) se ubica en el cromosoma 2 (2p13-14) y tiene 9 exones. La forma madura del péptido (419 residuos) sufre diferentes modificaciones postraduccionales además de la proteólisis de activación. Se ha descrito $\beta$-hidroxilación en Asp71, $\mathrm{N}$-glicosilación en los residuos 97, 248, 313 y 329, $\gamma$-carboxilación de nueve residuos Glu (E) con lo cual se forma el domino Gla (indispensable para su interacción con la cascada citoprotectora) ${ }^{16}$, además de la estabilización de las dos cadenas peptídicas de la forma activa mediante un puente disulfuro (155 y 262 residuos). ${ }^{17}$

Cuenta con cuatro dominios proteicos además del péptido de activación. El dominio Gla está constituido por los residuos 1-37 y dos regiones Epidermal Growth Factor (EGF)-Like, denominadas EGF-1 (46-92) y EGF-2 (93136) ${ }^{16,17}$ El péptido de activación está formado por los residuos ubicados en las posiciones 158 a 169 y el dominio activo de la proteasa está constituido por los residuos ubicados en las posiciones 170 a $419 .{ }^{16,17}$ Las actividades anticoagulantes que dependen de la interacción con estructuras celulares y subcelulares, al igual que las antiinflamatorias y antiapoptóticas que dependen de la interacción con el receptor endotelial de la proteína $\mathrm{C}$ (EPCR), son responsabilidad del dominio Gla. ${ }^{17,18,19} \mathrm{La}$ descripción de estos detalles ha posibilitado el desarrollo de variantes recombinantes sin actividades anticoagulantes o citoprotectoras. ${ }^{20-23}$

La indispensabilidad de la aPC se ha confirmado con la alta tasa de complicaciones vasculares en pacientes homo y heterocigóticos para mutaciones que reducen la actividad de la misma. ${ }^{24,25,26}$ En ratones con una marcada disminución en la actividad de la proteína (no ausencia total), se ha descrito una fuerte tendencia procoagulante, además de una marcada hiperreactividad inflamatoria. ${ }^{27}$

Contrario a lo que podría pensarse, la trombina no tiene mucha afinidad por el zimógeno. La interacción de estas dos proteínas es lo suficiente estable (clivando el zimógeno y produciendo $\mathrm{aPC}$ ) sólo cuando la trombina se une a la trombomodulina y la proteína $\mathrm{C}$ lo hace a su receptor, localizado en la membrana citoplasmática de las células endoteliales (Endotelial Protein C Receptor, EPCR). ${ }^{28}$ Aunque la distribución del EPCR y la trombomodulina en las células de la pared endotelial es similar, puede decirse que las moléculas de aPC se producen en la microvasculatura general, pero con claras variaciones de un órgano a otro. ${ }^{28}$

\section{La función de la aPC}

Alprincipiosólo se reconoció su efecto anticoagulante, tras haber encontrado una relación inversa entre su concentración plasmática y el riesgo de muerte de pacientes con sepsis severa. Hoy se acepta que esta actividad depende de la inactivación proteolítica de los factores Va y VIIIa de esta cascada. ${ }^{22} \mathrm{Su}$ efecto antiinflamatorio y antiapoptótico se debe a la interacción que la molécula tiene con el EPCR y con el receptor 1 de proteasa activada (PAR-1), lo cual ocurre después de que el zimógeno es clivado y la proteína activada permanece en interacción con el receptor. ${ }^{29-32}$ Reconociendoquela intensidad del efecto antiinflamatorio de aPC depende de la estabilidad de la interacción entre la molécula y su receptor, y considerando que la afinidad de la forma activa y el zimógeno por el receptor es similar, podría pensarse que un receptor con mayor afinidad por la aPC podría llevar a una mayor intensidad de la respuesta terapéutica en sepsis severa. 


\section{EI sistema de transducción antiinflamatorio y antiapoptótico}

Los receptores activados por proteasas (PARs) se encuentran ligados a proteínas $\mathrm{G}$ heterotriméricas y se activan mediante el corte de su extremo $\mathrm{N}$-terminal (dominio extracelular), con lo cual se expone un dominio de fuerte afinidad por el cuerpo del receptor, lo cual modifica su conformación molecular transfiriendo esta señal y activando la proteína $\mathrm{G} .{ }^{33,34}$

Se conocen al menos cuatro miembros de esta familia de receptores (PARl-4), los cuales se activan por una extensa lista de proteasas de serina y han sido relacionados con un amplio espectro de procesos celulares relacionados con la remodelación tisular, en especial el tejido vascular. ${ }^{35}$ Se ha propuesto que estos receptores actúen como sensores de la homeostasis proteolítica, proceso que se vealterado en patologías como cáncer, sepsis y afecciones isquémicas generadas y/o preservadas por disfunción inflamatoria y apoptótica. ${ }^{36,37,38}$

El representante prototípico de esta familia de receptores, PAR-1, es estimulado en forma específica por la trombina, pero además por otras proteasas como la plasmina, el factor Xa de la coagulación y la proteína $\mathrm{C}$ activada. ${ }^{34}$ Sin embargo, no deja de ser llamativo el hecho de que dos proteasas de serina (trombina y aPC) actúen de igual forma sobre el mismo receptor, pero generen una respuesta celular tan diferente. ${ }^{39-45}$

Se ha propuesto que estas diferencias se deben, al menos en parte, a variación en la eficiencia de clivaje del dominio extracelular del receptor. ${ }^{39}$ No puede ocultarse, por lo tanto, lo discontinuo que es el cuerpo conceptual existente respecto al mecanismo mediante el cual la aPC logra su efecto citoprotector. La actividad del PAR-1 en respuesta al estímulo de la aPC induce activación de kinasas por mitógeno (MAPK) y otras cadenas de fosforilación de kinasas de acción secuencial, lo cual en última instancia modifica el fenotipo de especies celulares y subcelulares relacionadas con diferentes procesos como coagulación, inflamación y apoptosis. ${ }^{42}$

Se ha demostrado que el efecto transcripcional de la aPC podría resumirse en represión de los factores proinflamatorios y proapoptóticos, además de la inducción de factores antiinflamatorios y antiapoptóticos. $\mathrm{La}$ aPC reprime la actividad y expresión genética del NF- $\mathrm{kB}$, lo cual genera reducción de la actividad de las vías de citoquinas y la inducción de moléculas de adhesión por parte del FNT- $\alpha$. Por otro lado, induce la producción de proteínas de la familia de Bcl-2 y reprime la de p53, Bax y relacionadas. ${ }^{43,44,45}$

\section{Efecto antiinflamatorio}

El papel antiinflamatorio de la aPC se fundamenta en sus efectos sobre células endoteliales y leucocitarias. Su estímulo a las primeras ocasiona menor liberación de mediadores de inflamación y regulación a la baja de las moléculas de adhesión vascular. Esta misma molécula induce disminución de la adhesión e infiltración leucocitaria, además de que reprime su liberación de mediadores inflamatorios (incluyendo citokinas), lo cual reduce la intensidad del daño tisular. ${ }^{46,47,48}$ Además baja el potencial quimiotáctico de diferentes agentes y protege la indemnidad de la barrera endotelial. ${ }^{49} \mathrm{La}$ activación dePAR-1 por aPC también lleva a la supresión de la actividad de factores transcripcionales activados por inflamación como la proteína activadora 1 (AP-1), c-FOS y FosB, que de manera directa inducen la producción de la molécula 1 de adhesión intracelular (ICAM-1) y la proteína quimioatrayente 1 de monocitos (MCP-1) en células endoteliales, al igual que c-Rel, miembro de la familia de NF- $\kappa B .45$

Sorprende que el patrón transcripcional generado por aPC en células no perturbadas, no es muy diferente al causado por la trombina. Por el contrario, cuando las células endoteliales fueron estimuladas con FNT- $\alpha$, el patrón transcripcional generado por la aPC se distanció del causado por la trombina ${ }^{42} \mathrm{La}$ transcripción de p 53 es fuertemente inducida por la trombina, mientras que la aPC induce su represión; de hecho, la aPC no sólo reprime la transcripción de p53, ya que también lo hace con su traducción..$^{50}$ Caso similar se presenta con la trombospondina-1, que sufre represión de su transcripción por parte de aPC y no por la trombina. ${ }^{42,50}$

No obstante, ambas proteasas (aPC y trombina) regulan a la alta su receptor(PAR-1) en células endoteliales bajo 
estrés a pesar de que lo "utilizan" de una manera bien diferente. ${ }^{29}$ Aunque el papel antiapoptótico de la aPC se mencionará más adelante, debe considerarse que esta función también tiene un impacto antiinflamatorio. La represión de la respuesta apoptótica de monocitos y células endoteliales, tiene una notoria consecuencia antiinflamatoria ya que estas células tienen una enorme capacidad fagocitaria, por lo cual su accionar llevaría a la reducción del estímulo antigénico. ${ }^{51}$

\section{Actividad antiapoptótica}

La actividad antiapoptótica de aPC depende, al menos en parte, de su interacción con EPCR y PAR-1, y su estímulo bloquea la respuesta apoptóptica por las vías intrínseca y extrínseca. Este efecto tiene diferentes implicaciones, dentro de las cuales se puede incluir la mejora en el pronóstico de cuadros clínicos como sepsis severa. ${ }^{52}$

No se conoce el mecanismo intracelular mediante el cual aPC bloquea la apoptosis. Se ha demostrado que esta molécula reduce la tasa transcripcional y transduccional de p53 en células endoteliales expuestas a hipoxia. ${ }^{50}$ Lo más sorprendente es que un escaso número de productos génicos (incluyendo p53) muestra dependencia de la actividad de PAR-1. ${ }^{42}$ En células endoteliales cerebrales bajo hipoxia, el estímulo de aPC bloqueó la hiperreactividad de Bax, mantenimiento de los niveles de la proteína antiapoptótica $\mathrm{Bcl}-2 .^{50}$

\section{Estabilización de la barrera endotelial}

La pérdida de la estabilidad de la barrera endotelial es uno de los factores centrales que sustentan el desarrollo físiopatológico de la sepsis y es un requisito indispensable para el establecimiento de edema, hipotensión y potenciación de la inflamación.

Se sabe que el efecto estabilizante de esta proteína se centra en la producción de la esfingosina 1-fosfato (S1P), como consecuencia de la inducción de la kinasa 1 de esfingosina (SphK-1)..$^{48} \mathrm{~S} 1 \mathrm{P}$ es un segundo mensajero que actúa mediante el estímulo de un receptor acoplado a proteínas $\mathrm{G}\left(\mathrm{S}_{\mathrm{P}} \mathrm{P}_{1}\right)$, el cual hace parte de la familia genética de diferenciación endotelial. La actividad de este sistema induce la reducción de la permeabilidad endotelial y estabiliza los componentes del citoesqueleto dependientes de las kinasas de la familia Rho y de las activadas por mitógeno (MAPKs). ${ }^{52-55}$

Conservando la tendencia antes descrita, el estímulo de la trombina también tiene un efecto contrario al de la aPC en lo relacionado con la estabilización de la barrera endotelial. ${ }^{38}$ Se ha demostrado que aunque la señal de la trombina también es transducida por el sistema de S1P y en ambos casos los receptores son reclutados a los dominios membranales de clatrina, el estímulo de la trombina depende de la actividad de Rho, mientras que la señal de la aPC depende de la actividad de Rac. ${ }^{54}$

\section{Referencias}

1. Angus D, Linde-Zwirble, Lidicker J, Clemont G, Carcillo J, Pinsky M. Epidemiology of severe sepsis in the United States: analysis of incidence, outcome, and associated costs of care. Crit Care Med. 2001; 29: 1303-10.

2. Martin G, Mannino D, Eaton S, Moss M. The epidemiology of sepsis in the United States from 1979 through 2000. N Engl J Med. 2003; 348: 1546-54.

3. Riedemann N, Guo R, Ward P. The enigma of sepsis. J Clin Invest. 2003; 112:460-67.

4. Hotchkiss RS, Karl IE. The pathophysiology and treatment of sepsis. N Engl J Med. 2003; 348:138-50.

5. Riedemann NC, Guo R, Ward PA. Novel strategies for the treatment of sepsis. Nat Med. 2003; 9:517-24.

6. Hattori Y, Takano K, Teramae H, Yamamoto S, Yokoo H, Matsuda N. Insight into sepsis therapeutic design based on the apoptotic death pathway. J Pharmacol Sci. [serie en Internet]. 2010 [citado 2011 Feb 1]; 114 (4):[aprox. 12 p.]. Disponible en: http://www.jstage.jst.go.jp/article/jphs/advpub/0/ advpub_1011100472/_article

7. Yan S, Brandt T, Correll N, Um S, Bourdage J. Evaluation of anti-activated protein $\mathrm{C}$ antibody development in patients with severe sepsis form four clinical studies with drotrecogin alpha (activated). J Thromb Haemost. 2009 Nov;7(11):1787-94.

8. Tang B, McLean A, Dawes I, et al. Gene-expression profiling of grampositive and gram-negative sepsis in critically ill patients. Crit Care Med. 2008; 36 (4): 1125-28.

9. Fitting C, Dhawan S, Cavaillon J. Compartmentalisation of endotoxin tolerance. J Infect Dis 2004; 189: 1295-1303.

10. Bemard G, Margolis B, Shaines H, Ely E, Wheeler A, Levy H, et al. Extended evaluation of recombinant human activated protein $C$ United States trial (ENHANCEUS): a single-arm, phase 3B, multicenter study of drotrecogin alfa (Activated) in severe sepsis. CHEST. 2004; 125 (4): 2206- 16.

11. Martin G, Brunkhorst FM, Janes JM, et al. The international PROGRESS registry of patients with severe sepsis: drotrecogin alfa (activated) use and patient outcomes. Crit Care 2009; 13: R103. 
12. Zeni F, Freeman B, Natanson C. Anti-inflammatory therapies to treat sepsis and septic shock: a reassessment. Crit Care Med. 1997; 25: 1095-1100.

13. Natanson C, Esposito CJ, Banks SM. The sirens' songs of confirmatory sepsis trials: selection bias and sampling error. Crit Care Med. 1998; 26 : 1927-31.

14. Marshall JC. Clinical trials of mediator-directed therapy in sepsis: what have we learned?. Intensive Care Med. 2000;26 Suppl 1:S75-83.

15. Mosnier L, Zlokovic B and Griffin J. The cytoprotective protein c pathway. Blood. 2006; 109 (8): 3161-72.

16. Griffin J, FernándezA, Gale A and Mosnier L. Activated protein C. J Thromb Haemost. 2007; 5 (Suppl 1): 73-80.

17. Esmon C. The endothelial cell protein $C$ receptor. Thromb Haemost. 2000; 83: 639-43.

18. Liaw P, Mather T, Oganesyan N, Ferrell G, Esmon C. Identification of the protein $\mathrm{C} /$ activated protein $\mathrm{C}$ binding sites on the endothelial cell protein $\mathrm{C}$ receptor. Implications for a novel mode of ligand recognition by a major histocompatibility complex class 1- type receptor. J Biol Chem 2001; 276 : $8364-70$

19. Ni Ainle F, O'Donnell J, Johnson J, Brown L, Gleeson E, Smith O, et al. Activated protein $\mathrm{C} \mathrm{N}$-Linked glycans modulate cytoprotective signaling function on endothelial cells. J Biol. Chem. 2011 Jan 14; 286(2):1323-30.

20. Mosnier L, Yang X, Griffin J. Activated protein C mutant with minimal antiocoagulant activity, normal cytoprotective activity, and preservation of thrombinactivable fibrinolysis inhibitor-dependent cytoprotective functions. J Biol Chem. 2007; 282 (45): 33022-33.

21. Bae J, Yang L, Manithody $\mathrm{Ch}$, et al. Engineering a disulfide bond to stabilize the calcium-binding loop of activated protein $C$ eliminates its anticoagulant but not its protective signaling properties. J Biol Chem. 2007; 282 (12) 9251-59.

22. Mosnier L, Zampolli A, Kerschen E, Schuepbach R, Benerjee Y, Fernández $\mathrm{J}$, et al. Hyperantithrombotic, noncytoprotective Glul49Ala-activated c mutant. Blood. 2009; 113 (23): 5970-78

23. Kerschen E, Fernandez J, Cooley B, et al. Endotoxemia and sepsis mortality reduction by non-anticoagulant-activated protein C. J Exp Med. 2004; 10: $2439-48$.

24. Douglas A, Rafferty H, Hodgkins P, Nagra A, Foulds N, Morgan M, et al. Persistent fetal vasculature and severe protein $\mathrm{C}$ deficiency. Mol Syndromol. 2010; 1 (2): 82-6.

25. Allaart C, Poort S, Rosendaal F, Reitsma P, Bertina R, Briet E. Increased risk of venous thrombosis in carriers of hereditary protein $\mathrm{C}$ deficiency defect. Lancet. 1993; 341: 134-38.

26. Millar D, Johansen B, Berntorp E, Minford A, Bolton-Maggs P, Wensley R, et al. Molecular genetic analysis of severe protein $C$ deficiency. Hum. Genet. 2000; 106: 646-53.

27. Lay A, Liang Z, Rosen E, Castellino F. Mice with a severe deficiency in protein $\mathrm{C}$ display prothrombotic and proinflammatory phenotypes and compromised maternal reproductive capabilities. J Clin Invest. 2005; 115 : 1552-61.

28. Weiler, H. Regulation of inflammation by the protein $\mathrm{C}$ system. Crit Care Med. 2010; 38 (2): S18-S25.
29. Mosnier $\mathrm{L}$ and Griffin J. Protein $\mathrm{C}$ anticoagulant activity in relation to antiinflammatory and antiapoptotic activities. Front Biosci. 2006; 11: 2381-99.

30. Mosnier L, Zlokovic B and Griffin J. The cytoprotective protein C pathway. Blood. 2006; 109 (8): 3161-72.

31. Seeley S, Covic L, Jacques S, et al. Structural basis for thrombin activation of a protease-activated receptor: inhibition of a intramolecular liganding. 2003; 10: 1033-1041.

32. Hartmut W. Regulation of inflammation by the protein $\mathrm{C}$ system. Crit Care Med. 2010, 38 (2): S18-S25.

33. Seeley S, Covic L, Jacques S, et al. Structural basis for thrombin activation of a protease-activated receptor: Inhibition of a intramolecular liganding 2003; 10: 1033-41.

34. Coughlin S. Thrombin signaling and protease activated receptors. Nature 2000; 407: 258-64

35. Griffin C, Srinivasan Y, Zheng Y, Huang, W and Coughlin S. A role for thrombin receptor signaling in endotelial cells during embryonic development. Science. 2001; 293: 1666-70.

36. Even-Ram S, Uziely B, Cohen P, et al. Thrombin receptor over expression in malignant and physiological invasion processes. Nat. Med. 1998; 4 : 909-14

37. Zain J, Huang X, Feng X,Nierodzik M, Li J and Karpat-kin S. Concentrationdependent dual effect of thrombin on impaired growth/apoptosis or mitogenesis in tumor cells. Blood 2000; 95: 3133-38.

38. Boire A, Covic L, Agarwal A, et al. PAR1 is a matrix metalloprotease-1 receptor that promotes invasion and tumorigenesis of breast cancer cells Cell. 2005; 120: 303-13.

39. Ludeman M, Kataoka H, Srinivasan $Y$, et al. PARl cleavage and signaling in response to activated protein $\mathrm{C}$ and thrombin. J Biol Chem. 2005; 280 : 13122-28.

40. Coughlin SR, Camerer E. PARticipation in inflammation. J Clin Invest. 2003; 111: 25-27.

41. Ludeman $M$, Kataoka $H$, Srinivasan $Y$, et al. PAR 1 cleavage and signaling in response to activated protein $\mathrm{C}$ and thrombin. J Biol Chem. 2005; 280:13122-28.

42. Riewald M, Ruf W. Protease-activated receptor-1 signaling by activated protein $\mathrm{C}$ in cytokine perturbed endothelial cells is distinct from thrombin signaling. J Biol Chem. 2005; 280: 19808-14.

43. Franscini N, Bachli E, Blau N, et al. Gene expression profiling of inflamed human endothelial cells and influence of activated protein $\mathrm{C}$. Circulation. 2004; 110: 2903-09.

44. Pereira C, Bachil E, Schaer D, Schoedon G. Transcriptome analysis revelaled unique genes as targets for the anti-inflamatory action of activated protein $\mathrm{c}$ in human macrophages. PLoS One. 2010; 5 (10): el 5352.

45. Joyce D, Gelbert L, Ciaccia A, DeHoff B and Grinnell B. Gene expression profile of antithrombotic protein $\mathrm{C}$ defines new mechanisms modulating inflammation and apoptosis. J Biol Chem. 2001; 276: 11199-203.

46. Murakami $\mathrm{K}$, Okajima $\mathrm{K}$, Uchiba $\mathrm{M}$, et al. Activated protein $\mathrm{C}$ attenuates endotoxin-induced pulmonary vascular injury by inhibiting activated leukocytes in rats. Blood. 1996; 87: 642-47. 
47. Feistritzer $\mathrm{C}$, Riewald M. Endothelial barrier protection by activated protein C through PARI-dependent sphingosine 1-phosphate receptor-1 crossactivation. Blood. 2005; 105:3178-84.

48. Nick J, Coldren C, Geraci M, Poch K, Fouty B, O‘Brien J, et al. Recombinan human activated protein $\mathrm{C}$ reduces human endotoxin-induced pulmonary inflammation via inhibition of neutrophil chemotaxis. Blood. 2004; 104: 3878-85.

49. Niessen F, Furlan-Freguia C, Fernández J, Mosnier L, Castellino F, Weiler $\mathrm{H}$, et al. Endogenous EPCR/aPC-PAR-1 signalling prevents inflammationinduced vascular leakage and lethaly. Blood. 2009; 113 (12): 2859-66.

50. Cheng T, Liu D, Griffin JH, et al. Activated protein C blocks p53-mediated apoptosis in ischemic human brain endothelium and is neuroprotective. Nat Med. 2003; 9: 338-42.
51. Stephenson D, Toltl L, Beaudin S and Liaw P. Modulation of monocyte function by activated protein C, a natural anticoagulant. J Immunol. 2006; 177: 2115-22.

52. Hotchkiss R, Chang $\mathrm{K}$, Swanson $\mathrm{P}$, Tinsley $\mathrm{K}$, Hui J, Klender $\mathrm{P}$, et al. Caspase inhibitors improve survival in sepsis: a critical role of the lymphocyte. Nat Immunol. 2000; 1: 496-501.

53. McVerry B, Garcia J. Endothelial cell barrier regulation by sphingosine 1phosphate. J Cell Biochem. Mosnier L and Griffin J 2004; 92: 1075-85.

54. Burridge K, Wennerberg K. Rho and Rac take center stage. Cell. 2004; 116 167-79.

55. Singleton P, Dudek S, Chiang E and Garcia J. Regulation of sphingosine 1phosphate-induced endothelial cytoskeletal rearrangement and barrier enhancement by S1P1 receptor, $\mathrm{PI} 3$ kinase, Tiam $1 / R a c 1$, and alpha-actinin FASEB J. 2005; 19: 1646-56.

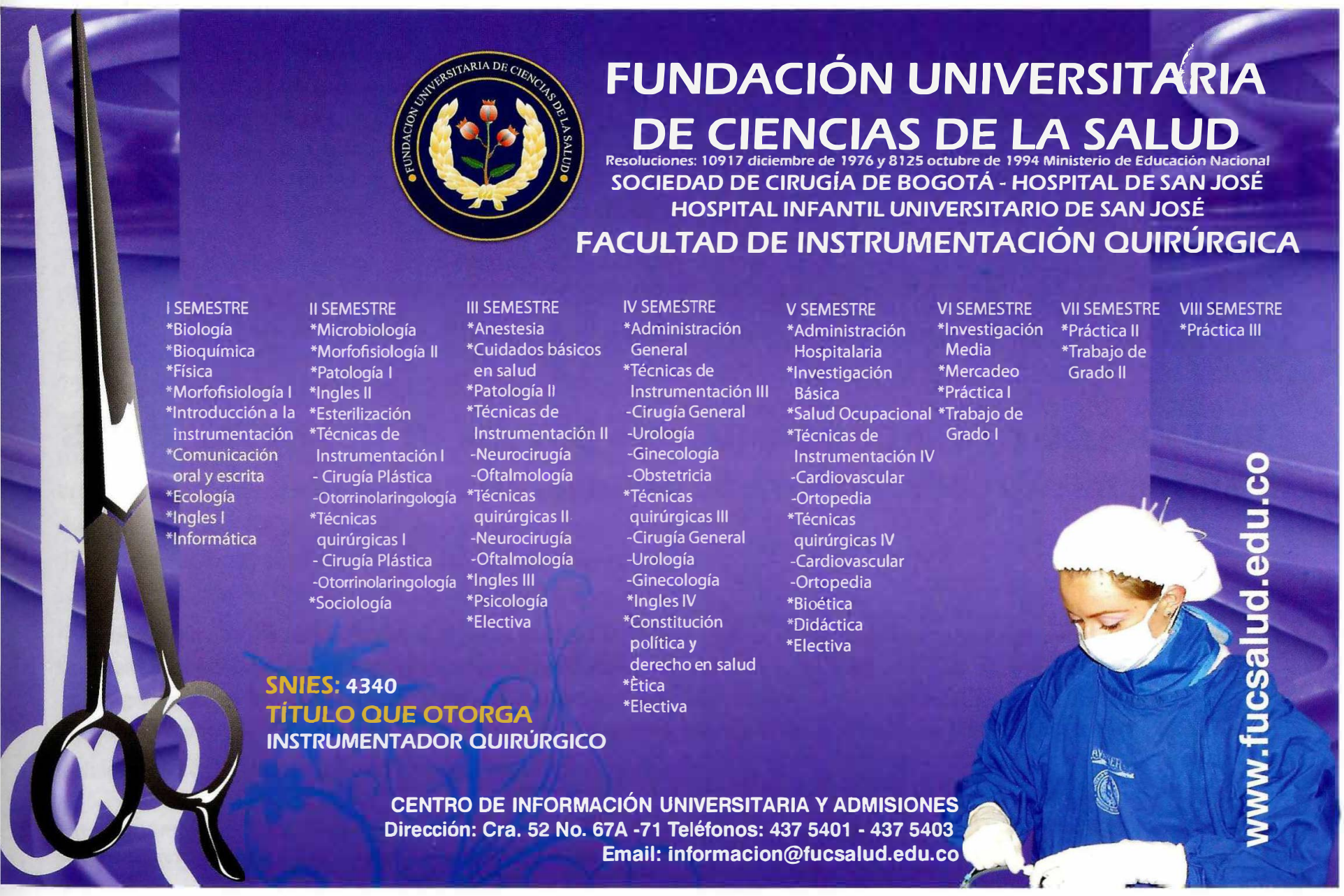

